\title{
TINJAUAN ADDENDUM WAKTU PELAKSANAAN PROYEK PEMBANGUNAN JEMBATAN KAMPUNG BARU NAN XX KOTA PADANG
}

\author{
Nasrul $^{1}$ dan Beni Mulyadi ${ }^{2}$ \\ Dosen Teknik Sipil ITP, Mahasiswa Teknik Sipil ITP ${ }^{2}$ \\ nasrullenk@gmail.com ${ }^{1}$ \\ DOI: http://dx.doi.org/10.31869/rtj.v2i2.1382
}

\begin{abstract}
Abstrak: Manajemen proyek merupakan sebuah disiplin keilmuan dalam hal perencanaan, pengorganisasian, pengelolaan (menjalankan serta pengendalian) untuk dapat mencapai tujuan-tujuan proyek. Peranan manajemen proyek dalam suatu pelaksanaan proyek konstruksi sangatlah penting, mengingat proses pelaksanaan proyek konstruksi bersifat dinamis. Rencana pelaksanaan pada sebuah proyek seringkali diawali dengan asumsi-asumsi normatif, sedangkan dalam proses pelaksanaannya banyak sekali hal-hal tak terduga terjadi yang mengakibatkan terlambatnya suatu pekerjaan sehingga mengakibatkan terjadinya perubahan, mulai dari cuaca, faktor sosial lingkungan sampai dengan penyesuaian volume kontrak. Kompensasi dari perubahan itu salah satunya adalah perpanjangan waktu pelaksanaan kontrak, namun perubahan ini tentu harus disikapi secara teknis dan administrasi karena tanpa dokumen yang lengkap perubahan-perubahan tadi tentu tidak menjadi sah. Addendum kontrak adalah salah satu bukti sah nya suatu perubahan, karena addendum walaupun secara fisik terpisah dari perjanjian pokoknya akan tetapi secara hukum addendum tetap melekat pada perjanjian pokok itu sendiri. Tulisan ini memuat mekanisme serta syarat untuk mengajukan addendum perpanjangan waktu pelaksanaan kontrak sehingga addendum layak diterima secara aturan yang berlaku.
\end{abstract}

Kata Kunci: manajemen proyek, addendum kontrak, perpanjangan waktu

Abstract: Project management is a scientific discipline in terms of planning, organizing, managing (running and controlling) to be able to achieve project objectives. The role of project management in implementing a construction project is very important, considering the process of implementing construction projects is dynamic. The implementation plan for a project is often preceded by normative assumptions, whereas in the implementation process a lot of unexpected things occur that result in the delay of a job resulting in changes, ranging from weather, environmental social factors to the adjustment of contract volume. One of the compensation for the changes is an extension of the time of contract implementation, but this change certainly must be addressed technically and administratively because without a complete document the changes would certainly not be valid. The contract addendum is one of the valid proofs of a change, because the addendum although physically separate from the principal agreement will be legally addendum still attached to the principal agreement itself. This paper contains the mechanism and conditions for submitting an addendum for the extension of the implementation of the contract so that the addendum is eligible to be accepted in the applicable rules.

Keywords: project management, addendum contract, extra time

\section{PENDAHULUAN}

Manajemen proyek merupakan sebuah disiplin keilmuan dalam hal perencanaan, pengorganisasian, pengelolaan (menjalankan serta pengendalian) untuk dapat mencapai tujuan-tujuan proyek. Terkait dengan fungsi pengelolaan (menjalankan serta pengendalian) ada aspek yang sangat berperan dalam suatu proyek, yaitu aspek administrasi.

Dalam realita praktek konstruksi seharihari aspek administrasi merupakan hal penting yang tidak boleh diabaikan oleh pihak penyelenggara proyek, baik dari pihak owner, konsultan supervisi maupun kontraktor. Seringkali administrasi oleh beberapa pihak dianggap tidak terlalu penting untuk diperhatikan, sehingga seringkali diabaikan. Padahal kelalaian dalam penyusunan administrasi proyek dapat menimbulkan permasalahan di kemudian hari yang bisa berdampak kurang baik kepada pelaku proyek itu sendiri, apalagi pada saat ini kelengkapan adminstrasi proyek telah menjadi tolak ukur tersendiri tentang keabsahan suatu proyek. 
Salah satu bagian dari administrasi proyek tersebut adalah dokumen kontrak.

\section{REVIEW LITERATUR}

Kontrak adalah kesepakatan perjanjian antara dua pihak atau lebih mengenai hal tertentu yang disetujui oleh mereka. Kontrak harus memuat Berita Acara kesepakatan antara pihak yang terlibat, syarat-syarat yang harus dilaksanakan selama proses pekerjaan serta perubahan-perubahan yang terjadi selama proses pekerjaan.Perubahan yang terjadi selama masa pekerjaan, baik itu waktu maupun biaya harus terdokumentasi dengan baik dan benar dalam dokumen kontrak yang dikenal dengan Addendum. Dalam dokumen addendum harus tergambar dengan jelas penyebab dan alasan perubahan yang terjadi disertai dengan data pendukung yang lengkap. Semua penyebab yang menjadi alasan dari perubahan tersebut harus memiliki dasar hukum dan landasan yang kuat sehingga addendum layak diterima.

Menurut Perpres Nomor .54 Tahun 2010 sebagaimana telah di ubah dengan Perpres Nomor.04 Tahun 2015 pasal 91 ayat 1 "contoh keadaan kahar yaitu: Bencana Alam, bencana non alam, bencana sosial,pemogokan, kebakaran dan gangguan industri."

Sebagaimana yang telah dituturkan Iman Soeharto "Sumber daya manusia dalam proyek adalah seluruh tenaga kerja yang dipergunakan sebagai masukan atau input pada suatu rangkaian kegiatan proyek untuk memperoleh hasil proyek telah ditetapkan".

\section{METODOLOGI PENELITIAN}

Dalam menyusun penelitian ini penulis mengumpulkan data:

I. Obsevasi

II. Wawan cara.

III. Literatur.

Metode ini dilakukan untuk memperoleh data yang didapatkan dilapangan sebagai sumber nyata tentang kebenaran dan penerapan teori.

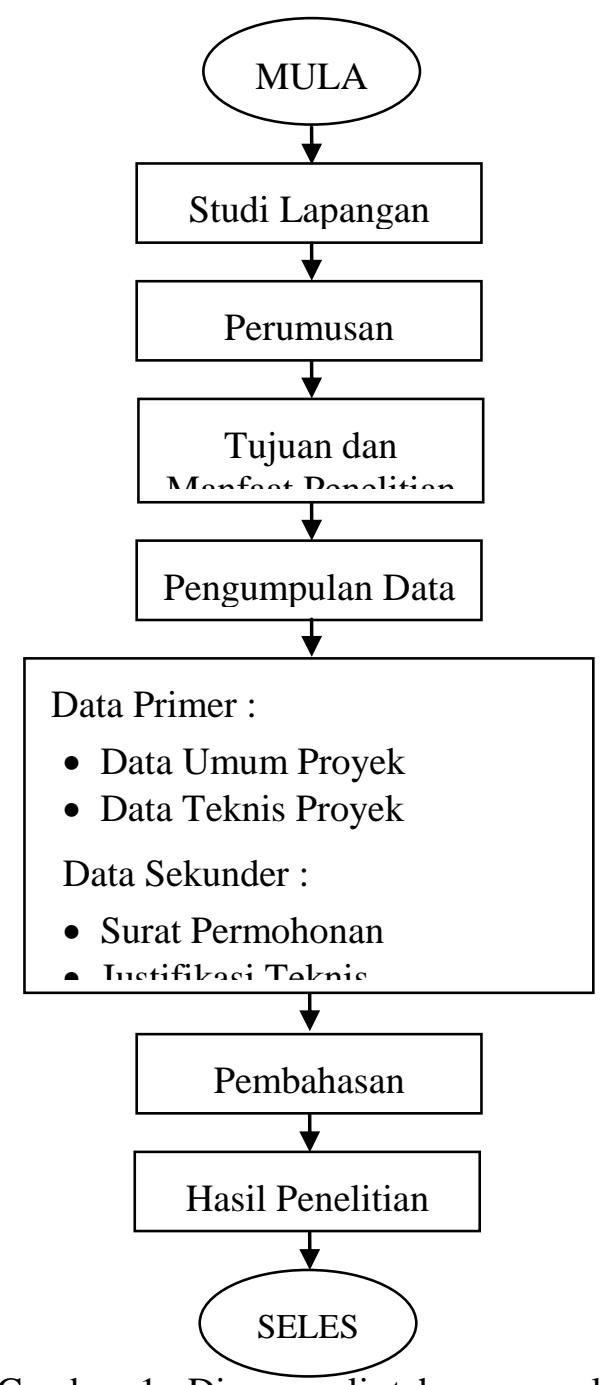

Gambar. 1 : Diagram alir tahapan penelitian

\section{HASIL DAN PEMBAHASAN \\ Analisis Masalah}

Pada proyek Penggantian Jembatan Kampung Baru Nan XX Kecamatan Lubuk Begalung, keterlambatan diakibatkan oleh beberapa hal, yaitu :

a. Masalah Sosial

Jembatan Kampung Baru Nan XX terletak antara dua Kelurahan, yaitu Kelurahan Kampung Baru Nan XX dan Kampung Jua Nan XX. Posisi ini menyebabkan pihak kontraktor harus melewati jalan kolektor untuk mencapai titik lokasi pekerjaan.

Kondisi ini dimanfaatkan oleh beberapa oknum yang berada pada perlintasan jalan menuju lokasi proyek untuk melakukan pungli sehingga sempat menghambat proses pekerjaan.

b. Perubahan volume/kuantitas pekerjaan berdasarkan hasil perhitungan lapangan.Waktu antara masa perencanaan 
dan masa pelaksanaan, sehingga kondisi di lapangan telah mengalami perubahan, namun tidak lebih $10 \%$ dari volume kontrak.

Dalam hal ini PPK dimungkinkan untuk melakukan perubahan kontrak sebagaimana yang telah diatur dalam Perpres Nomor.54 Tahun 2010 pasal 87 ayat 1, PPK bersama penyedia jasa dapat melakukan perubahan kontrak yang meliputi :

a. Menambah atau mengurangi volume pekerjaan yang tercantum dalam kontrak.

b. Menambah dan/atau mengurangi jenis pekerjaan.

c. Mengubah Spesifikasi Teknis pekerjaan sesuai dengan kebutuhan lapangan; atau

d. Mengubah jadwal pelaksanaan. dan pasal 87 ayat 2, Pekerjaan tambah sebagaimana dimaksud pada ayat (1) dilaksanakan dengan ketentuan :

a. tidak melebihi $10 \%$ (sepuluh perseratus) dari harga yang tercantum dalam perjanjian/kontrak awal.

b. Tersedianya Anggaran.

c. Cuaca

Cuaca adalah kondisi alam yang tidak dapat diubah oleh manusia, manusia hanya mampu menanggulangi permasalahan yang ditimbulkan oleh cuaca tersebut. Hal inilah yang terjadi dengan pelaksanaan proyek Penggantian Jembatan Kampung Baru Nan XX, pekerjaan sering kali terhenti karena kondisi cuaca yang ekstrim dimana curah hujan dengan intensitas tinggi turun secara tiba-tiba. Kondisi ini menyebabkan hanyutnya perancah yang dipasang pada saat proses erection (pemasangan) rangka jembatan.

Oleh karena yang menyebabkan pekerjaan ini menjadi lambat adalah faktor alam dan bukan kesengajaan dari pihak kontraktor, maka owner harus menyikapi hal ini sehingga pihak yang terlibat dalam pekerjaan tidak ada yang dirugikan,

\section{Pembahasan Masalah}

Pada dasarnya perencanaan schedule suatu proyek didasarkan pada asumsi-asumsi dalam keadaan normatif. Sedangkan kondisi yang terjadi dilapangan sering kali sulit diprediksi (dinamis), hal ini menyebabkan suatu struktur organisasi proyek harus kuat dan saling mendukung satu sama lain. Struktur organisasi yang kuat tersebut maksudnya adalah para personil harus cakap pada tugas masingmasing. Sedangkan saling mendukung maksudnya setiap personil harus mengetahui tugas dan fungsi masing - masing sehingga tidak terjadi tumpang tindih tugas, akan tetapi saling mengisi pekerjaan selama proyek berlangsung.

Sebagaimana yang telah dituturkan Iman Soeharto ( dalam Naldi 2011:2) "Sumber daya manusia dalam proyek adalah seluruh tenaga kerja yang dipergunakan sebagai masukan atau input pada suatu rangkaian kegiatan proyek untuk memperoleh hasil proyek telah ditetapkan".

Melihat begitu pentingnya peranan sumber daya manusia dalam kelangsungan suatu proyek maka pada pembahasan kali ini dimulai dari peranan personil yang ada pada pekerjaan Penggantian Jembatan Kampung Baru nan XX.

a. Personil

Pada Pelaksanaan proyek ini masing masing personil telah melaksanakan tugasnya dengan benar seperti yang dijabarkan berikut ini :

1) Site Manager

Site Manager adalah orang yang bertanggung jawab pada pelaksanaan pekerjaan secara keseluruhan, baik biaya, waktu dan mutu. Pada saat pelaksanaan pekerjaan Site manager telah menampilkan peranannnya dengan baik dimana dia bisa segera menemukan solusi apa yang harus dilakukan untuk mengatasi masalah keterlambatan pekerjaan baik secara administrasi proyek maupun metoda pelaksanaan dilapangan.

2. Pelaksana Proyek

Pelaksana bertanggung jawab terhadap kelangsungan pekerjaan dilapangan.

1. Juru ukur adalah orang yang mampu melakukan pengukuran kerangka horizontal (poligon) dan kerangka vertikal serta mampu memetakan situasi.

2. Tenaga Keuangan: Mampu menjaga kestabilan cash flow dengan baik sehingga dalam 
pelaksanaan pekerjaan tidak terjadi kendala keuangan.

3. Logistik: Orang yang bertanggung jawab mengatur arus barang dan sumber daya lainnya ke suatu tempat dengan tujuan suksesnya suatu pekerjaan.

Berdasarkan peranan yang telah dijabarkan diatas maka semua pihak telah menjalankan tugas sesuai dengan fungsinya sehingga owner dapat berkoordinasi dengan baik.

\section{Addendum Perpanjangan Waktu Pelaksanaan Kontrak}

Addendum perpanjangan waktu pelaksanaan kontrak adalah perubahan kontrak yang berupa perpanjangan waktu pelaksanaan kontrak karena adanya perubahan kondisi lapangan, keadaan kahar, dan/atau peristiwa kompensasi sehingga menuntut perpanjangan waktu pelaksanaan.

Menurut Perpres Nomor .54 Tahun 2010 sebagaimana telah di ubah dengan Perpres Nomor.04 Tahun 2015 pasal 91 ayat 1 "contoh keadaan kahar yaitu: Bencana Alam, bencana non alam, bencana sosial,pemogokan, kebakaran dan gangguan industri."

Berdasarkan penjelasan diatas, kondisi pekerjaan pada proyek Jembatan Kampung Baru Nan XX masuk dalam kategori kahar, dimana bencana alam banjir telah menerjang lokasi pekerjaan dan itu diperkuat dengan pernyataan bencana dari aparat setempat (Kelurahan).

Mencermati kondisi tersebut, dan mengacu kepada Perpres Nomor.54 Tahun 2010 sebagaimana telah di ubah dengan Perpres Nomor.04 Tahun 2015 pasal 91 ayat 5 "keterlambatan pelaksanaan pekerjaan yang diakibatkan oleh keadaan kahar tidak dikenakan sanksi", maka pihak kontraktor berhak untuk mendapatkan perpanjangan waktu karena kondisi yang dialami bukan karena kesengajaan tapi lebih karena kondisi alam yang tidak dapat diprediksi.

\section{Mekanisme Addendum Perpanjangan Waktu Pelaksanaan Kontrak}

Sesuai dengan aturan yang ada, addendum perpanjangan waktu diperbolehkan dalam pelaksanaan proyek Langkah-langkah yang harus dilakukan dalam mengajukan Addendum perpanjangan waktu pelaksanaan kontrak adalah :

1. Mengajukan permohonan perpanjangan waktu.

Pihak Kontraktor yang akan melakukan Addendum perpanjangan waktu pelaksanaan kontrak harus segera mengajukan permohonan secara tertulis kepada owner dalam hal ini Pejabat Pembuat Komitmen (PPK) dalam waktu paling lambat 14 (Empat Belas) hari setelah kejadian.

2 Peninjauan Pelaksaan Kontrak

Pejabat Pembuat Komitmen (PPK) selaku perwakilan pemerintah harus segera menindak lanjuti permohonan tersebut dalam bentuk Peninjuan ke lapangan dan peninjauan pelaksanaan kontrak. Untuk merealisasikan hal ini PPK dapat menunjuktim Teknis yang telah di tunjuk sebelumnya.

atau tidak.

3 Menerbitkan Justifikasi Teknis

Justifikasi Teknis adalah suatu gagasan atau ulasan yang berbentuk uraian mengenai hasil pengujian teknis yang dijabarkan dalam bentuk kalimat, sehingga dapat dipastikan hasilnya mampu mengatasi berbagai hal yang berkaitan tentang pelaksanaan pekerjaan. Kesimpulan dari Justifikasi Teknis dituangkan dalam dokumen kontrak Addendum. Dalam penerbitannya Justifikasi Teknis melibatkan Pihak Kontraktor, Konsultan Supervisi dan Owner.

4 Rekomendasi

Rekomendasi dihasilkan berdasarkan peninjauan lapangan dan peninjuan pelaksanaan kontrak. Isi dari rekomendasi adalah hal - hal yang harus dilakukan oleh PPK dalam menindak lanjuti permohonan perpanjangan waktu dari kontraktor.

\section{Analisa Pelaksanaan}

Jembatan Kampung Baru Nan XX menghubungkan antara Kelurahan Kampung Baru Nan XX dan Kelurahan Kampung Jua. Jembatan dengan struktur rangka baja ini mempunyai bentang sepanjang $50 \mathrm{M}$.

Pada tahap awal proses pelaksanaan, pihak kontraktor bersama konsultan supervisi melakukan pengukuran ulang terhadap keadaan 
lapangan dengan tujuan memastikan kembali volume kontrak sesuai dengan kondisi lapangan. Walaupun ditemukan perbedaan tapi secara prinsip konsultan supervisi menyatakan perencanaan telah sesuai dan pekerjaan dapat dilanjutkan, karena perbedaan yang ditemukan tidak melebihi $10 \%$ darivolume kontrak awal.

Pada mulanya realisasi pekerjaan fisik dilapangan sesuai dengan apa yang di targetkan, ini tergambar dari progress time schedule pelaksanaan pekerjaan. Realisasi fisik mulai terganggu pada minggu ke 20 (dua puluh), dimana pekerjaan mulai memasuki proses pemasangan rangka baja. Hal ini disebabkan oleh cuaca yang kurang mendukung, dimana telah terjadi banjir yang menghanyutkan perancah untuk memasang rangka baja.

Kejadian ini memberi tingkat ketergantungan terhadap pekerjaan yang lain, karena ada beberapa item pekerjaan yang hanya bisa dilakukan setelah proses pemasangan rangka selesai.

Melihat kondisi ini owner melalui konsultan supervisi memberikan surat teguran dan ditindak lanjuti dengan undangan untuk melakukan rapat SCM (Show Cause Meeting) guna membahas langkah-langkah apa saja yang harus dilakukan untuk memacu progres pekerjaan. Dalam rapat ini kontraktor memaparkan apa yang menjadi peyebab keterlambatan pekerjaan. Penjelasan dari kontraktor ditanggapi oleh konsultan supervisi dengan menjelaskan bahwa percepatan pekerjaan agak sulit dilakukan karena faktor utama penyebab terhambatnya pekerjaan adalah curah hujan yang tinggi. Menambah peralatan dan tenaga kerja tidak menjadi solusi disini karena tetap saja pekerjaan tidak bisa dilakukan

Melihat kondisi yang terjadi serta merujuk kepada aturan yang ada rapat memutuskan untuk memberi perpanjangan waktu pelaksanaan kepada pihak kontraktor.

Menyikapi hal ini pihak kontraktor segera menindaklanjuti dengan mengajukan addendum perpanjangan waktu kepada pihak direksi pekerjaan sesuai dengan aturan yang berlaku. Proses addendum diawali dengan surat permohonan dari pihak kontraktor pada tanggal 29 Agusutus 2017, tidak ingin kehilangan waktu PPK segera menindaklanjuti permohonan dari kontraktor dengan mengundang pihak yang terlibat dalam proyek seperti PPTK, Pengawas Pekerjaan, Konsultan Supervisi dan Tim Teknis untuk melakukan pemeriksaan lapangan bersama. Surat yang dikeluarkan pada tanggal 30 Agustus 2017 tersebut menjadwalkan pemeriksaan lapangan bersama pada hari Kamis tanggal 31 Agustus 2017. Pihak-pihak terkait memeriksa keadaan lapangan serta dituangkan secara tertulis dalam bentuk Berita Acara yang memuat kondisi lapangan serta alasan terjadinya perubahan. Berdasarkan hasil pemeriksaan yang telah dilakukan maka kontrak awal akan ditinjau ulang sesuai dengan keadaan yang terjadi sekarang. Rumusan-rumusan terhadap peninjauan kontrak dibuatkan dokumen tertulis berupa Berita Acara Peninjauan Kontrak. Hasil pemeriksaan bersama merekomendasikan agar perpanjangan waktu diberikan selama 28 (dua puluh delapan) hari, ini mengacu kepada waktu yang hilang karena gangguan bencana alam. Hal ini dibuktikan dengan time schedule pelaksaan yang menggambarkan keterlambatan pekerjaan pada saat lokasi dilanda bencana. Hasil-hasil inilah yang dirangkum sehingga menjadi sebuah kontrak addendum.

\section{PENUTUP \\ Simpulan}

Setelah penulis menyelesaikan penelitian pada proyek Penggantian Jembatan Kampung Baru Nan XX Kecamatan Lubuk Begalung ini maka penulis dapat menarik kesimpulan sebagai berikut:

1. Manajemen pelaksanaan pada proyek Penggantian Jembatan Kampung Baru Nan XX Kecamatan Lubuk Begalung secara umum berfungsi dengan baik. Hal ini terbukti dengan adanya koordinasi yang baik antar pesonil menyikapi banjir yang melanda lokasi proyek, sehingga dapat diputuskan langkah apa yang harus di ambil di lapangan.

2. Mengacu kepada Peraturan Presiden Nomor.54 Tahun 2010 sebagaimana telah diubah dengan Peraturan Pesiden Nomor.04 Tahun 2015, addendum waktu diperbolehkan pada situasi tertentu.

3. Penyebab terjadinya penambahan waktu pada proyek Penggantian Jembatan Kampung Baru ada 2, yaitu : 1. Perubahan volume pekerjaan /Contrak Change Order 
(CCO) 2. Bencana Alam (banjir) yang

\section{Saran}

melanda lokasi proyek.

1. Dalam pelaksanaan proyek diperlukan koordinasi yang baik antara Owner, konsultan dan kontraktor agar pelaksanaan pekerjaan dapat berjalan dengan baik dan benar.

2. Perencanaan awal harus sesuai dengan kondisi yang ada dilapangan agar tidak sering terjadi perubahan rencana kerja sehingga tidak menghabiskan banyak waktu dalam melakukan perubahan.

\section{DAFTAR PUSTAKA}

Gray Clive, dkk.1997. Pengantar Evaluasi Proyek. Jakarta: Gramedia Pustaka Utama

Handoko Hani.2001. Manajemen Proyek. Jakarta

Liputo Benyamin. 1988. Pengantar Manajemen. Jakarta: Depertemen Pendidikan dan Kebudayaan

Peraturan Presiden Republik Indonesia Nomor 54 Tahun 2010, Bogor.

Peraturan Presiden Republik Indonesia Nomor 04 Tahun 2015, Jakarta

Sarno Riyanarto.2012. Analisis dan Desain Berorientasi Servis untuk Aplikasi Manajemen Proyek.Yogyakarta: Andi Yogyakarta

Soeharto Iman.2002. Study Kelayakan Proyek Akhir. Jakarta: Erlangga

Soeharto Iman. 1999. Manajemen Proyek. Jilid 1. Jakarta: Erlangga 